\title{
A inserção dos processos contemporâneos nos cursos de arquitetura, urbanismono e design: a experiência da disciplina de Espaço e Forma 2.
}

The insertion of contemporary processes in the courses of architecture. urbanism and design: The experience of Scape and Shepe 2 class.

\author{
> Marina Pires de Castro Aguiar Vale \\ Universidade Federal do Ceará, Brasil \\ marinapires.design@gmail.com \\ > Anna Luisa Castanheira Costa \\ Universidade Federal do Ceará, Brasil \\ costannaluisa@gmail.com
}

\author{
> Neliza Maria e Silva Romcy \\ Universidade Federal do Rio Grande do Norte, Brasil \\ neliza.romcy@gmail.com
}

> Daniel Ribeiro Cardoso

Universidade Federal do Ceará, Brasil

daniel.br@mac.com

\begin{abstract}
Digital media and project-applied IT are redefining contemporary project concepts and cementing a new vanguard for project. As such, it proves necessary to bring over to the academic context the debate over this approach to the teaching of architecture, urbanism and design. At the Architecture and Urbanism Department in the Federal University of Ceará (DAU-UFC), resulting in the creation of a group of classes referred to as Space and Shape (EF) comprised of three stages: EF1, EF2, and EF3. This paper aims to present the class of Space and Shape 2, including its creation, implementation, and partial results.
\end{abstract}

Keywords: Contemporary processes, Education, Modeling, Tools.

\section{Introdução}

Quando se reflete acerca da era digital, tornar-se nítido e evidente como uma gama de novas tecnologias da Informática Aplicada ao Projeto tem influenciado o processo projetual contemporâneo. Nas últimas décadas, o papel do projetista tem sido revisto e repensado. Enquanto os típicos meios de projetar do lápis, papel e borracha eram associados às atividades de adicionar e apagar, os novos meios enfatizam, ainda, relacionar e reparar, exigindo um pensamento explícito sobre a natureza das relaçóes entre os elementos projetados (WOODBURY 2010).

Os meios digitais não são mais associados apenas à representação final, mas integrados ao longo de todo processo de desenvolvimento, como ferramenta de auxílio ao projetista, viabilizando e otimizando procedimentos que seriam inviáveis em uma metodologia tradicional de projeto.

Desse modo, a partir do reconhecimento dos novos meios digitais para o desenvolvimento de uma produção contemporânea, englobando arquitetura e design, mostrou-se necessário incentivar sua discussão no âmbito acadêmico, tanto como forma de apresentação desse novo pensamento e de seus conceitos pertinentes, quanto como possibilidade de permitir aos alunos seu uso em projetos futuros ao longo de sua construção acadêmica e profissional.

Diante desse panorama, são colocados dois eventos significativos dentro do Departamento de Arquitetura e Urbanismo da Universidade Federal do Ceará(DAU-UFC) viabilizando a experiência a ser apresentada: a proposta de um novo Projeto Político
Pedagógico(PPP), ocorrido em 2010, e a criação do curso de Design dentro do mesmo departamento no ano de 2011.

Após quase meio século de funcionamento do curso, a revisão do PPP buscou compreender as mudanças ocorridas no cenário da arquitetura tanto em escala regional quanto global, discutindo possíveis mudanças do curso, e refletindo sobre a essência do ensino e da prática da arquitetura e do urbanismo no mundo atual; baseadas, principalmente, nas transformaçóes no modo de vida do homem, das especificidades do desenvolvimento da sociedade brasileira, e dos rumos daju tecnologia (PPP, 2010).

Em conjunto, ocorreu a criação do curso de Design da Universidade Federal do Ceará(UFC), com ênfase em Produto e Gráfico, devido à necessidade de discussão da temática e demanda por profissionais da área no estado.

O cenário descrito viabilizou uma reflexão acerca da necessidade de trazer ao âmbito acadêmico uma abordagem atual relacionada às novas possibilidades da Informática Aplicada ao Projeto.

O tema traz desafios náo apenas sobre como as construçóes são projetadas, mas como são fabricadas e construídas, pois o potencial gerador e criativo dos meios digitais, juntamente aos avanços de fabricação estão abrindo novas dimensóes no processo de projeto (KOLAREVIC, 2001). No contexto nacional, ainda nâo se teria tomado consciência de que tais meios surgiram como ferramentas de apoio e se tornaram fundamentais para todo o processo de projeto, o que levaria à necessidade de atençáo por parte do meio acadêmico a essas novas tecnologias (PUPO, 2009). 
Dentro do DAU-UFC essas abordagens repercutiram na criação de um grupo de pesquisa, o Laboratório de Experiência Digital(LED) sob a orientação do Prof. Dr. Daniel Cardoso, que busca aprofundar estudos quanto à informática aplicada ao projeto e suas consequências ao processo projetual e seu ensino. Conta-se, ainda, com a implementaçáo de uma Oficina de Fabricação Digital, institucionalizada como FabLab UFC, como ambiente de suporte tecnológico para as novas atividades de ensino, pesquisa e extensão a serem colocadas em discussáo sobre o tema.

Nesse contexto, buscou-se transmitir aos discentes de forma prática as mudanças ocorridas no meio projetual, com a aplicação de três disciplinas em caráter processual, com aumento gradativo de complexidade e aprofundamento dos temas. Foi utilizado como base o processo de aprendizagem através da reflexão-na-ação: o aluno parte do reconhecimento e aplicação de regras e operaçóes padráo, para raciocinar sobre problemáticas características da profissão, até ser capaz de enfrentar novas formas de compreensão e ação (SCHÖN, 2000).

As disciplinas de Espaço e Forma compóem o eixo curricular dos cursos de Arquitetura e Urbanismo e de Design pertinente a compreensão formal, composição e capacidade de expressão. As duas disciplinas iniciais são ministradas no primeiro ano letivo de ambos os cursos e a terceira é oferecida em caráter optativo.

Em Espaço e Forma 1(EF1), os alunos desenvolvem estudos quanto a processos lógicos aplicáveis ao projeto e princípios de estruturação da forma com uso de regras, como Teoria Geral dos Sistemas, Gestalt e Gramática da Forma. A produção das composiçóes é realizada por processos artesanais para incorporar aos alunos a necessidade de analisar o produto em meio físico e desenvolver suas habilidades manuais. Em Espaço e Forma 2(EF2) os estudantes são introduzidos a abordagens projetuais contemporâneas e o uso das novas ferramentas computacionais. Por meio do ensino prático de solução de problemas, é realizada a transição dos processos em meio físico aos digital. Em Espaço e Forma 3(EF3), disciplina optativa e de aprofundamento, os discentes sáo estimulados ao pensamento crítico com processos mais complexos e o ensino do pensamento algorítmico, com ênfase no meio digital.

Dentro do contexto de implementação do conjunto de disciplinas "Espaço e Forma" (EF) nos cursos de Arquitetura e Urbanismo e Design, o enfoque será dado à disciplina intermediária Espaço e Forma 2, por se tratar de uma disciplina obrigatória nova, cujo conteúdo destaca as tecnologias e processos contemporâneos de estudo da forma e espaço.

\section{Metodologia}

Visando apresentar a experiência realizada no desenvolvimento da nova disciplina EF2, dividiu-se a metodologia em duas etapas principais: estruturação da disciplina e aplicação nas turmas iniciais.

A estruturação da disciplina teve início com o levantamento bibliográfico sobre as temáticas pertinentes à abordagem, como superfícies complexas; lógicas matemáticas aplicáveis ao estudo da forma; e processos generativos e paramétricos. Como referência, também foi adotada a experiência didática do Professor David
Sperling na tradução intersemiótica do conceito de movimento para uma proposição arquitetônica (SPERLING e OLIVEIRA, 2011).

A partir das referências adotadas, a disciplina foi dividida em:

1. Leitura de textos e realização de seminários com apresentação de conceitos pertinentes à linguagem e processos contemporâneos. Dentre as temáticas abordadas_nesse momento, destacam-se conceitos matemáticos como; a fita de moebius, os fractais, o diagrama de voronoy e a equação de fibonacci. Os alunos são levados a compreender os conceitos e apresentá-los ao restante da turma, a partir de exemplos encontrados nos campos da arquitetura, design, artes e natureza. Essa etapa permite a discussão do arcabouço teórico que será utilizado nas fases posteriores e gera um banco de referências com a participação dos próprios alunos.

2. Realização de um experimento físico-químico para a geração de formas com ausência de clichês, embasado no conceito de diagrama de Francis Bacon (DELEUZE, 2007), que defende o descontrole e a desconstruçáo como ferramentas para a obtenção de formas puras livres de pré-significados, visando a construção de uma proposição formal não esperada. Todo o processo do experimento é documentado por fotografia e vídeo, e então estudado frame a frame para a escolha de um "momento" formal, que será trabalhado como referência ao longo da investigação proposta. (Figura1)

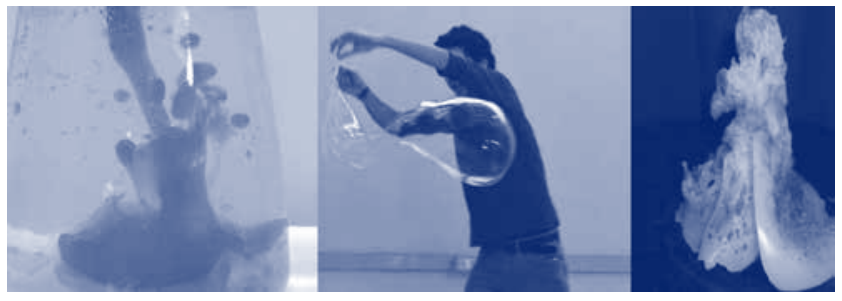

Figura 1: Experimentos físico-químicos, recipiente contendo água e óleo recebia uma porçáo de sal gerando as formas pela diferença de densidade. Bolhas de sabão gigante. Cera de vela derretida derramada em jato d'agua corrente. Elaborada pelos autores.

3. Elaboração de estudos em croquis da forma escolhida na etapa anterior, onde os alunos desenvolvem perspectivas e as vistas superior, lateral direita e frontal, conferindolhe um tratamento tridimensional. Os estudos em croqui são utilizados como base para a modelagem elaborada no software Rhinoceros 3D, permitindo a colaboração entre diferentes meios de representação, tanto para uma melhor compreensão da forma a ser proposta, quanto para o desenvolvimento das habilidades de percepção tridimensional por parte dos alunos. (Figura 2)

4. Apropriação da forma no desenvolvimento de uma proposta arquitetônica ou de design de produto, a partir da definição de um conceito coerente com a forma adotada durante o experimento físico-químico. Destaca-se ao 
longo do processo a capacidade dos alunos de articular o conceito defendido, a forma previamente adotada e a proposta final aplicada. No curso de arquitetura, são disponibilizadas duas opçóes de terrenos para que os alunos apliquem suas propostas, podendo escolher entre uma escala de edificação ou de intervenção urbana. No curso de design, os alunos desenvolvem um produto a partir do conceito por eles definido, apresentando aspectos como materiais, uso e escala humana.

5. Materialização da proposta em processo aditivo da fabricação digital por impressão 3D para o fechamento do ciclo e maior apreensão visual da proposta, ressaltando a importância da materialização para uma compreensão total do projeto. Ocorre também a apresentaçáo do projeto, na qual os alunos devem colocar todo o processo de desenvolvimento, defesa do conceito e imagens finais.

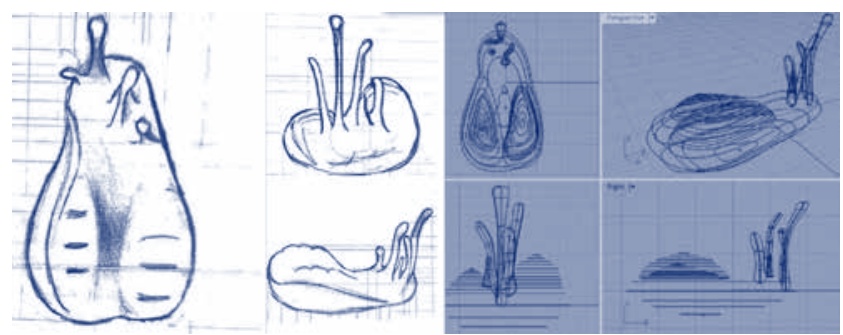

Figura 2: Processo de estudos por croquis com as vistas superior, frontal e lateral direita. Ao lado, modelagem tridimensional em Rhinoceros 3D. Elaborada pelos autores.

Após a estruturação da disciplina, realizou-se o acompanhamento de sua aplicação em três turmas: primeiramente, na turma 2013.1 na arquitetura, para verificação de sua proposta; e posteriormente nas turmas 2013.2 dos cursos de arquitetura e design, para sua validação.

\section{Resultado}

A primeira aplicação da disciplina (2013.1) apresentou resultados parcialmente positivos, visto que os alunos demonstraram crescimento conceitual e reflexivo, contudo, com dificuldades ao longo do processo de modelagem que desviaram o foco do curso, dando-lhe a ideia de uma disciplina fundamentada no ensino da ferramenta. A partir desse problema, foram revisadas as distribuiçóes das aulas, prolongando-se a abordagem conceitual inicial e as discussóes teóricas, enquanto o estudo da ferramenta foi intensificado com a criaçáo de grupos de estudos extra classe, desenvolvido pelos monitores da disciplina.

Assim, na segunda aplicação da disciplina (2013.2), o ensino da ferramenta teve início em paralelo às discussóes teóricas, mas fora de sala de aula, possibilitando uma otimizaçáo no processo de modelagem dos discentes, maior aprofundamento no conteúdo teórico e mais tempo para a experimentaçáo aplicada à proposta final.

Apesar da disciplina ser encerrada com a apresentação final da proposta arquitetônica ou de design de produto desenvolvida pelos alunos, as avaliaçóes ocorrem de forma processual, considerando-se não apenas o produto final alcançado, mas seu desenvolvimento ao longo do processo.

Dentro os resultados obtidos nas aplicaçôes da disciplina, serão apresentados a seguir três exemplos para ilustrar esse processo.

A primeira proposta, pertencente ao curso de arquitetura e urbanismo e denominada pelo conceito de "Forças Invisíveis", teve como ponto de partida o experimento físico-químico baseado na reação sonora da tinta guache em exposição à diferentes frequências. As diferentes formas emergentes a essa reação foram desmembradas e passaram por um processo de desconstrução, até seu elemento mínimo e sintetizador, que foi modelado e multiplicado, com posterior aplicação de superfícies compostas. A forma final levou à sugestão de um complexo educativo e centro cultural, com amplos espaços de convivência e anfiteatro nomeado por Instituto Sete. (Figura 3)

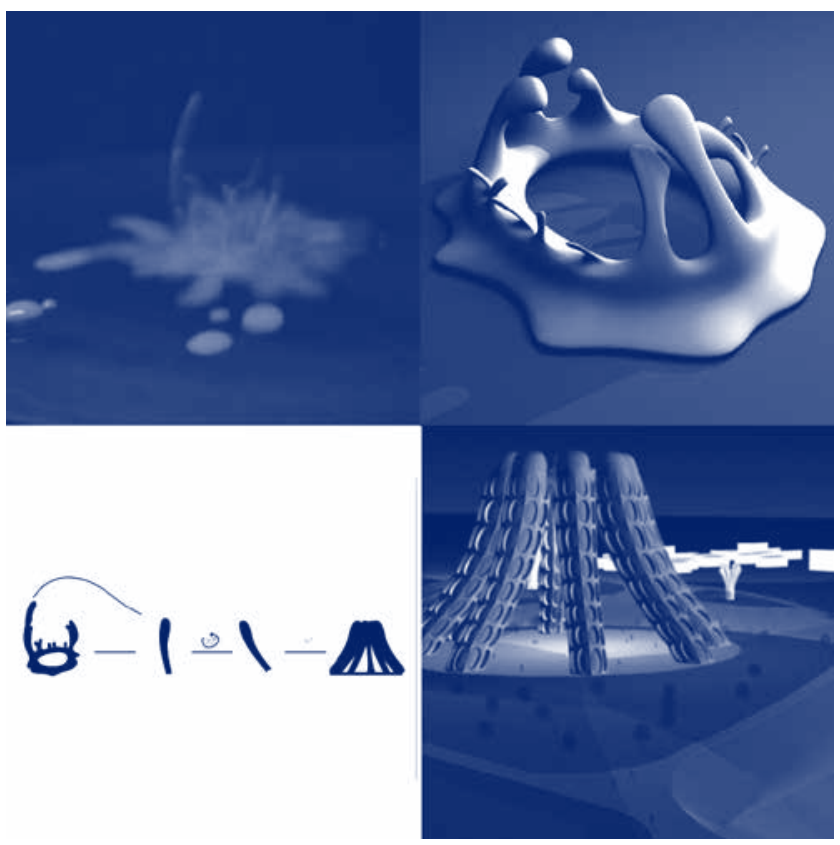

Figura 3: Processo de desenvolvimento do Instituto Sete. Experimento físicoquímico, de tinta reagindo a ondas sonoras modelagem inicial, processo de apropriação da forma inicial e proposta final. Elaborada pelos autores.

A segunda proposta no curso de arquitetura e urbanismo resultou no projeto "Mantos", composto por um museu com áreas de galerias e restaurante.

Para a concepçáo da forma inicial, uma bailarina com o corpo coberto por mangueiras de LED dançou em correspondência aleatória, por resposta sensorial do corpo à exposição sonora. Seus movimentos foram registrados em fotografia de longa exposição, resultando em um efeito denominado pela equipe como "tecido paramétrico". A apropriação da forma resultou no alongamento e suavização de suas curvas, sendo finalizado com o processo construtivo de "waffle", buscando o efeito de desmaterialização percebido no experimento físico. (Figura 4) 


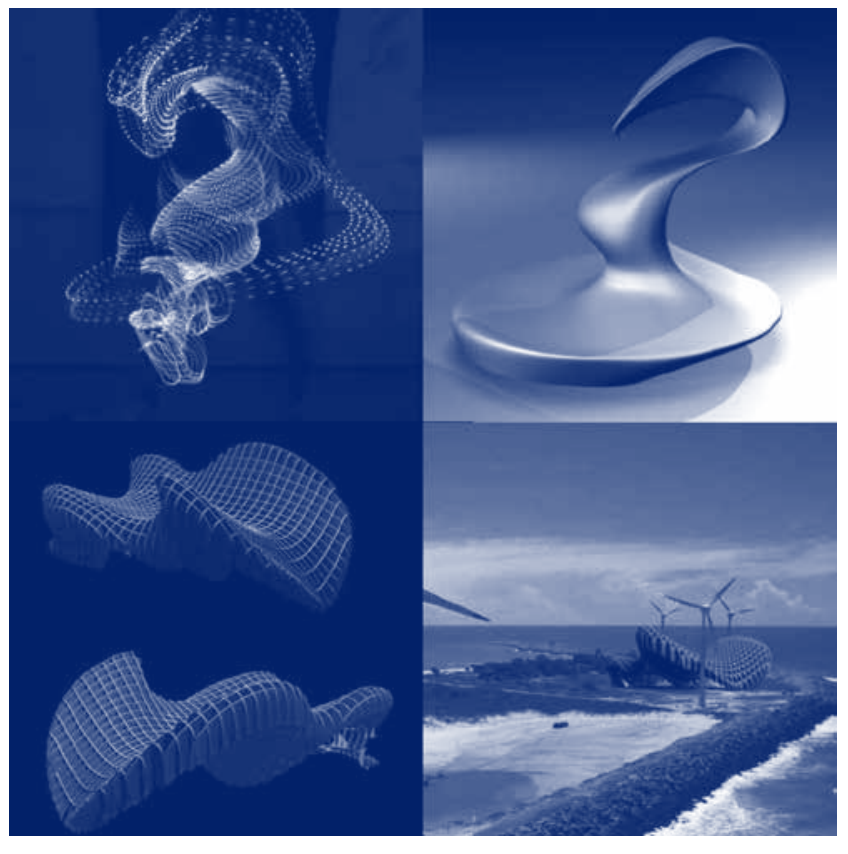

Figura 4: Processo de desenvolvimento do Projeto Mantos. Experimento físicoquímico, do movimento das luzes devido a música registrado por fotografia de longa exposiçấo, modelagem inicial, processo de apropriação da forma associada a técnica construtiva de "waffle", e proposta final. Elaborada pelos autores.

A proposta pertencente ao curso de Design se apresenta em um desenho inovador de motocicleta. $\mathrm{O}$ conceito abordado pela equipe consistiu no estudo do movimento, e repercutiu em um experimento físico-químico baseado no princípio do fluído não -newtoniano. Quando exposto à pressão e a agitação, esse fluído tornasse rígido e sólido, enquanto após aliviada a tensão, ele tende à forma líquida novamente. $\mathrm{O}$ composto foi colocado sobre uma caixa de som e reagiu à música nela tocada de acordo com a quantidade de graves e da intensidade de vibração do audio. A forma escolhida foi trabalhada exclusivamente por emergência formal, ou seja, a partir da forma inicial, foram realizadas alteraçóes em um processo próximo a escultura, repuxada e moldada, sem recortes, e sem perder as características iniciais. A forma por si ditou sua função e forma final.(Figura 5)

\section{Debate}

$\mathrm{O}$ artigo traz a experiência de estruturação da nova disciplina EF2, com o objetivo de introduzir nos cursos de Arquitetura e Design questôes relativas ao processo e ferramentas contemporâneas.

Diante desse contexto as principais contribuiçōes destacadas são: 1) a proposta da disciplina, não de maneira isolada, mas dentro de uma estratégia curricular mais ampla; 2) a estruturação da disciplina em um processo onde o aluno transcorre momentos de concepção, desenvolvimento da proposta e materializaçáo; 3) destaque para o embasamento teórico e a problematização presente nas novas abordagens contemporâneas, e não apenas no ensino tutorial da ferramenta.

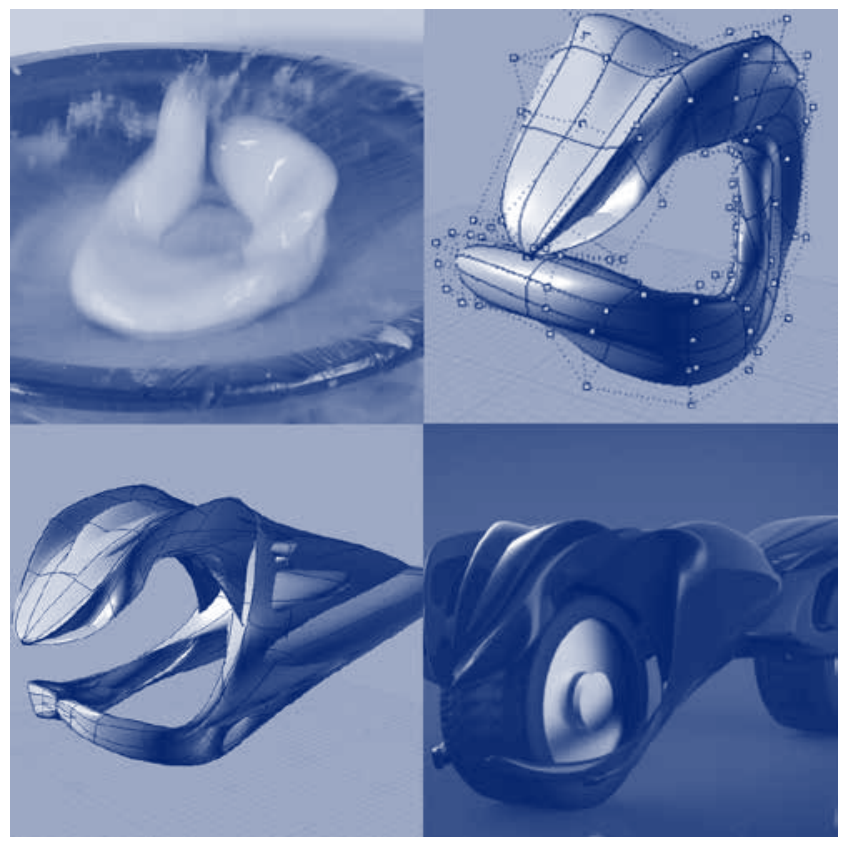

Figura 5: Processo de desenvolvimento do projeto de motocicleta. Experimento físico-químico, flúido não-newtoniado reagindo a ondas sonoras e vibração, processo inicial de apropriação da forma ainda pouco alterado, processo de modifiação da forma em estágio avançado e proposta final. Elaborada pelos autores.

Assim, busca-se ressaltar aos alunos a reflexão sobre as problemáticas envolvidas nas novas abordagens contemporâneas, que não se restringem a ferramentas e produtos, mas principalmente a novos processos.

\section{Referência}

DELEUZE, G. Francis Bacon: A lógica da Sensação. Rio de Janeiro: Jorge Zahar, 2007.

KOLAREVIC, B.. Designing and manufacturing architecture in the digital age. Architectural information management, 2001.

PUPO, R. Inserção da PROTOTIPAGEM e FABRICAÇÃO DIGITAIS no processo de projeto: um novo desafio para o ensino de Arquitetura. Tese (Doutorado) Engenharia Civil - Faculdade de Engenharia Civil, Universidade Estadual de Campinas, 2009.

SPERLING, D. M. ; OLIVEIRA, M. R. . Experimentação projetual no ensino de arquitetura apoiada por tecnologia de fabricação digital. In: XV Congresso da Sociedade Iberoamericana de Gráfica Digital, 2011, Santa Fé - Argentina. Sigradi Cultura Aumentada 2011. Santa Fé: FAU-UNL, 2011. p. 397-400.

SCHÖN, D. A. Educando o Profissional Reflexivo: um novo design para o ensino e a aprendizagem. Porto Alegre: Artmed Editora, 2000

CURSO DE ARQUITETURA E URBANISMO - UFC. Projeto Político Pedagógico. Fortaleza: (mimeo), 2010.

WOODYBORY, R. Elements of Parametric Design. Nova Iorque, Routledge, 2010. 